\title{
Conjoint Analysis of Tourist Choice of Hotel Attributes Presented in Travel Agent Brochures
}

Rubén Huertas-Garcia ${ }^{1, *}$, Marta Laguna García ${ }^{2}$ and Carolina Consolación ${ }^{3}$

${ }^{1}$ Department of Economics and Business Administration, Barcelona University, Barcelona, Spain

${ }^{2}$ Department of Administration and Marketing Research, Valladolid University, Segovia, Spain

${ }^{3}$ Department of Business Administration, Technical University of Catalonia, Barcelona, Spain

\section{ABSTRACT}

The purposes of this study are to demonstrate how it is possible to determine which attributes are the most important in the final choices of tourists who use a travel agent brochure as a source of information and how these attributes influence perceived value in a pre-purchase stage. We conduct the study in three phases: (i) a qualitative study, (ii) an experiment using choice-based conjoint analysis by means of a fractional factorial experimental design and (iii) another experiment using a full factorial derived from the same design. Results suggest advertisement size, a hotel's starred rating and price influence perceived value at this stage. The presence of a positive combined effect of price and advertising was found. Implications and directions for future applications are offered, focusing particularly on marketing services. Copyright @ 2012 John Wiley \& Sons, Ltd.

Received 05 November 2010; Revised 29 May 2012; Accepted 11 June 2012

Keywords: perceived value; choice-based conjoint analysis; tourist brochure; experiments in blocks.

\section{INTRODUCTION}

$\mathrm{D}$ espite the increasing importance of the Internet as a communication and distribution instrument, brochures continue

*Correspondence to: Rubén Huertas-García, Department of Economics and Business Administration, Barcelona University, Avda. Diagonal, 696, Barcelona, Spain.

E-mail: rhuertas@ub.edu to be a common source of information for tourists (Bieger et al., 2000; Andereck, 2005; Molina and Esteban, 2006). The influence information published in brochures has on the decision-making process means brochures play an important role in promoting tourist businesses and destinations. Several studies analyse the influence various sources of information have on destination choice. Andereck (2005) argued that evaluations of brochures by tourists influence interest in visiting a destination, and these evaluations influence the choice of destination as well. Hsieh and O'Leary (1993) reported that brochures are the third most common source of information used by travellers, after interpersonal communication from relatives and friends. In one of the most technologically advanced countries, Yamamoto and Gill (1999) found that brochures are one of the two most important sources of information used by Japanese travellers who buy travel packages.

More recently, Chiou et al. (2008) suggested that traditional brochures greatly influence behaviour in verbalizer consumers, those who prefer to process written or verbal information from sources such as relatives, friends or travel agents over pictorials. Ortega and Rodriguez (2007) found that brochures are one of the most important audio-visual formats for Spanish tourists seeking destination information. Molina and Esteban (2006) proposed a model of brochure utility and studied its significance as image generators. Clearly, the brochure is not an extinct product.

Despite the importance of tourist brochures as communication tools, little is known about their effectiveness. Some researchers call attention to large amounts of money spent by tourism distributers in brochure production but rarely 
demonstrate their usefulness or effectiveness in meeting objectives (Hodgson, 1993; Andereck, 2005). Little is known about the effect of tourist brochures as tools to promote destination and tourism organizations. There is also little empirical evidence concerning effects generated by layouts presented to tourists on brochures, especially in the pre-purchase stage. The literature contains sufficient evidence to suggest that the way information is presented, the layout, influences consumer evaluations and purchase intentions (Munger and Grewal, 2001; Rewtrakunphaiboon and Oppewal, 2008). The purpose of this study is to demonstrate that it is possible to determine the most important attributes people consider when choosing a hotel and using a travel agent brochure as a source of information. This paper reports results from a two-step experiment where the design of the second was derived from the results of the first. This process helps determine what kind of information displayed by a hotel in the tourist brochures influences a consumer's perceived value and choice.

\section{THE TOURIST CHOICE PROCESS AND INFORMATION SEARCHES}

Choosing a holiday destination is not a simple decision because selection is derived from a set of independent choices. It is a complex, multifaceted process in which choices are interrelated and evolve (Dellaert, et al., 1998). It is well established in consumer behaviour literature that the purchase decision process consists of five stages: problem recognition, information search, product options evaluation, purchase decision and postpurchase support (Kotler, 2000). The purchase process for a traveller begins when a consumer recognizes a need or unsolved problem, having received external stimulus usually from tourist advertisements that trigger thoughts on making a purchase.

In the context of tourism services, the purchase process is much more complex because travel includes various services (e.g. destination, transportation and hotel). Nicolau and Mas (2006) suggested that the process of choosing a tourist destination involves two phases of sequential decisions. The first phase is formed by two chronological decisions, the decision of whether to go on holiday and length of stay. The second phase involves selection of destination, a conditional decision because choice depends on length of holiday. Various socio-demographic factors including income, number of family members, age, environment and attitudes toward holidays influence both decision phases. Having made a selection, the decision process continues with a series of derivative decisions generally made prior to a trip: (i) accommodations, (ii) travel company, (iii) transportation and (iv) changes to adjust length of trip. The choice of accommodation is often made at a later stage in the decision-making process for a tourist trip.

The next stage involves searching for information about characteristics offered by service companies and their prices. Consumers use both internal and external information sources when making purchase decisions. Consumers typically use internal information from memory as the first source and then move to external searches by using a variety of sources, a process requiring considerable effort. Travellers often visit several travel agencies or search for information on the Internet. The two primary categories of destination factors are related to (i) activities tourists can experience at a destination such as sports, dining, historic sites, nightlife, shopping and outdoor recreation, and (ii) other destination characteristics such as price, accessibility, climate, health and safety, residential attitudes toward tourists, language barriers, availability and quality of accommodation, and air quality (Dellaert et al., 1998).

All sources of travel information including brochures help travellers make informed decisions. Planning and searching for information offer tourists the opportunity to reduce uncertainty risk and disappointing experiences (Roehl and Fesenmaier, 1992). Fodness and Murray (1999) suggested that for companies operating in a competitive market, it is essential to understand the search information process tourists follow. The more unfamiliar a destination is, the more time and effort must be spent on pre-purchase information searching (Andereck, 2005). Wicks and Schuett (1991) found that travellers who use brochure information as an aid when planning travel continue to use brochures as a guide or reference throughout a trip.

Once the tourist gathers enough information, the next step in the purchase decision process is evaluation. This is the third stage, involving 
evaluation of product or service options offered by various companies and examination of product attributes such as price and brand. (Gupta et al., 2004). Zhou (1997) evaluated the effectiveness of destination brochures requested by travellers, suggesting that of those who read the brochure, 50\% visited the destination and most consulted the brochure during the visit. Andereck (2005) found that tourists who have no knowledge about a tourist destination demonstrate greater interest in information contained in brochures than those who visited the destination previously.

This study focuses on the evaluation of alternatives, the third stage of the buying process. It is important to recognize that there exist various market segments with differing tastes and preferences; experiments require working with groups that are as homogeneous as possible so differences in responses demonstrate combinations of factors rather than socio-demographic respondent characteristics (Haaijer and Wedel, 2007). In this case, the target market chosen was students in their final year of university who wished to take a graduation trip for 4 days during the Easter holiday. The decision about destination and duration, 4 days prior to Easter day, was static, and participants searched for accommodations in travel agency brochures and on the Internet.

\section{PERCEIVED VALUE AND CONSUMER DECISIONS}

Choosing a hotel room or a trip from a brochure depends on the perceived utility people expect from the room or trip and the price. The marketing literature defines the relationship between perceived utility and price as perceived value. Zeithaml (1988, p.14) proposed a definition: 'perceived value is the consumer's overall assessment of the utility of a product based on perceptions of what is received and what is given'. What is received and what is given represent trade-offs between give and get components. Benefit components include intrinsic and extrinsic attributes, perceived quality and other relevant high-level abstractions, and sacrifice components include price and other non-monetary costs. Managers and academicians recognize a strong influence of perceived value on consumer behaviour, making it a priority for researchers (Hauser

Copyright (C) 2012 John Wiley \& Sons, Ltd. and Urban 1986, Zeithaml 1988, Dodds et al., 1991, Ostrom and Iacobucci 1995, Teas and Agarwal 2000, Gallarza and Gil, 2006).

Price is often a conflictive element because it plays a double role as an extrinsic product quality cue and a product choice monetary constraint (Erickson and Johansson, 1985). These price roles can be labelled as informational and allocation roles (Rao and Sattler, 2007). Although the two roles of price are clear and derive from disparate theoretical conceptions, measurements are difficult and tend to confuse the two when measured directly. In tourism literature, Naylor and Frank (2001) suggested that price bundling increases perceptions of value for first-time holidaymakers. A study by Rewtrakunphaiboon and Oppewal (2008) examines whether package information influences intentions to visit and choice of beach holiday destinations. On the basis of extant research, the authors assumed that the importance of an attribute increases when products display according to the attribute (Rewtrakunphaiboon and Oppewal, 2008, p.129). Accordingly, findings suggest that presenting price as a package heading (i.e. presenting packages with only price) increases intentions to visit and choice of beach holiday destinations among students.

Services such as travel products are perceived as riskier purchases than goods (Zeithaml, 1988). Because services are more difficult to evaluate and riskier to purchase, consumers use diverse processes and cues for evaluation. Searching for information is one heuristic used to reduce risks and help travellers make decisions. Travellers who have little information about a destination from internal sources (i.e. memory, friends and relatives) use external sources such as brochures and the Internet (Andereck, 2005). For purchasing services, extrinsic attributes become cues when information on intrinsic attributes is unavailable (Zeithaml 1988). Several researchers develop and test models of perceptions of value with particular emphasis on a buyer's extrinsic cues such as price and brand name as indicators of quality and value. Dodds et al. (1991) conducted a study to examine direct and indirect relationships between price, brand name and store name, and perceived quality, product value and willingness to buy. They argue that price alone is the most important cue of perceived quality; adding store and brand

Int. J. Tourism Res. (2012) DOI: $10.1002 /$ jtr 
name information has moderate effects. If a price changes from low to high, perceived value increases and at a point decreases significantly, impacting willingness to buy negatively. The negative effect of price on value perceptions reduces if brand or store name is provided. Price has a positive influence on perceived quality but negative effects on perceived value and willingness to buy.

Perceived value also depends on the framework under which customers conduct evaluations (Hempel and Daniel, 1993), defined as a dynamic variable. Perceptions of value change if an assessment is made before or after purchase (Woodruff 1997) and whether it is assessed before sale, at the moment of sale, at the moment of use or after use (Moliner et al., 2005). Some authors consider other factors that alter perceived value. Lee et al. (2007) reported that value depends on a consumer's characteristics and the type of product under consideration. Value is a latent construct not observed directly (Teichert and Shehu, 2007); most studies in this area use scales to estimate the latent component. We use stated preferences to estimate the value or utility generated by varying profiles in the pre-purchase stage.

\section{METHODOLOGY}

Because perceived value and utility are unobservable, they require scales or proxy variables to estimate them (Teichert and Shehu, 2007). According to Klein (1990), there are two methods to identify and measure consumer needs and desires: asking directly or deducing the motives from other kinds of data. The advantages of indirect methods include establishing robust causal relationships between attributes and customer evaluations. A popular device, choice-based conjoint analysis, is an indirect method used to obtain measurement of preferences (Haaijer and Wedel, 2007). During conjoint analysis' evolution over the last 40 years, there was a shift in the types of responses used for analysis from ranking, to ratings, and finally to choosing the best profiles (Elrod and Chrzan, 2007). The most frequent criterion for assessing a choice set was ratings of full profiles, evaluated individually (Wittink and Cattin, 1989). Since the late 1980s, the choice prevailed as the dominant criterion for evaluating profiles, estimated by aggregate multi-nomial logit models (Louviere et al., 2000; Street and Burgess, 2007). Implicit models are compensatory and decompositional, enabling analyses of the importance of each product's characteristics, starting with a customer's stated preferences. In this study, we demonstrate the process of designing a choicebased conjoint analysis and how it determines the value of extrinsic cues that, for a market segment, are used to choose a hotel room from a tourist brochure. We use one of the least common models, ranking, based on a one-sixth fraction from a $2^{8}$ full factorial design in eight twosize blocks in which the second profile of each block is a mirror image of the first.

\section{Choice-based conjoint analysis}

The process of evaluating the choice of accommodation from a brochure operates within discrete choice models (CMs). CM is a family of survey-based methodologies for modelling preferences for goods in which goods are described by their attribute levels. Respondents are presented with alternative descriptions of products differentiated by attributes and levels and rank the various alternatives, rating them or choosing those they prefer (Hanley et al., 2001). The form of evaluation (e.g. lexicographic, elimination by aspect, economic and attribute screening) that predominates among respondents in driving such selections remains elusive (Scarpa and Rose, 2008).

Choice model based on choosing the best option has several advantages over traditional ratings and rankings. Choice is often the behaviour of ultimate interest in a decision process because it estimates behaviours accurately. Models estimated from choice allow direct prediction of choices, avoiding the need for conjoint simulators (Elrod et al., 1992). Its primary disadvantage is that it works poorly with small samples because the process of choice contains minimal information concerning consumer preferences. A chosen option indicates which alternative is the most preferred, but it does not provide information about other alternatives not selected. A choice process implicitly entails consideration of multiple alternatives, but only one option is chosen; in a ranking process, all alternatives are considered (Elrod and Chrzan, 
2007). We propose a ranking model adjusted by a proportional odds ordinal logistic model (Train, 2009). The decision to use this model was based on two objectives. Estimations made by using all ranking information are more efficient, and efficiency is greatest when a full profile design is used. This improvement in efficiency allows more acceptable results with reduced samples. Ranking is consistent with consumer behaviour in both economy theory and with respect to the nature of preferences representing an ordered relationship (Frank, 2009). A typical choice-based conjoint analysis is characterized by several stages:

- Identification of relevant attributes of goods to be valued. The use of literature reviews, consultation with experts and qualitative techniques such as focus groups establishes these attributes.

- Assignment of a feasible, realistic range of plausible levels for attributes. Qualitative research or literature searches establish appropriate levels.

- Choose an experimental design for gathering data. The experimental design is based on statistical theory to combine levels of the attributes into alternative profiles presented to respondents. Whereas full factorial designs often generate an impractically large number of combinations for evaluation, fractional factorial designs and block designs reduce the number of combinations but with a concomitant loss of power.

- Profiles identified by the experimental design are grouped into choice sets and presented to respondents. Profiles can be presented to respondents individually, in respondent pairs or in groups.

- Measurement of preferences. Individual preferences are discovered in choice-modelling surveys by asking respondents to rank options, score them or choose those they prefer most. These methods of measuring preferences correspond with variations of modelling approaches.

- Estimation procedure. The model is adjusted using Ordinary Least Square (OLS) regression or maximum likelihood estimation.

In this study, preference differences between hotel listings indicated differences in value and tendency to rent a room. The theory of reasoned action posits behaviour intentions influences behaviours (Ajzen and Madden, 1986). Social psychology research suggests intentions are the best predictor of behaviours because they allow individuals to incorporate all relevant factors independently that influence behaviours (Fishbein and Ajzen, 1975). Several studies examine the relationship between purchase intentions and purchase behaviours for non-durable goods (Dowling and Staelin, 1994). The degree to which people express preferences is a reasonable predictor of purchase behaviours.

Qualitative research. Investigating the first two stages of the experimental process of conjoint selection, we began with qualitative research to identify the attributes considered relevant in the perceived value of choosing a hotel displayed in a travel agent's brochure. We evaluated aggregate utility generated by the sample of students from varying combinations of attributes offered by advertisements in a brochure. The fieldwork for the qualitative research was carried out in Segovia, Spain from November 2006 to February 2007. The use of university student samples for experimental research attracted the attention of many researchers recently (Gallarza and Gil, 2006; Rewtrakunphaiboon and Oppewal, 2008). We used a focus group with three smaller groups of eight students each based on a chosen destination of Punta Cana, Santo Domingo. The sessions were conducted with two travel agency brochures, asking openended questions and recording answers. After the sessions, we coded and classified answers to reveal relevant attributes. The data were coded using inductive category coding, consisting of labelling factors repeatedly found in text (Spiggle 1994). Similar processes are used in content analysis in the service literature (Tax et al., 1998), and the method is used extensively in studies of consumer behaviour to identify relationships within text (Spiggle, 1994).

The attributes gathered in the focus groups were as follows: the image and aesthetics of the illustrations in the advertisement were an important factor; aerial or panoramic images were preferred, although well-lit, nocturnal photos were also viewed favourably; the size of the illustrations and the hotel's starred rating 
were determining factors; five-star establishments displayed in large photographs were preferred; the structure of the buildings was very important; low, open buildings were preferred to high, square buildings, although there was no consensus concerning the size of the hotel; accessibility and proximity to the beach and restaurants were important; the starred rating was indicative of quality, but no importance was given to the ICTE's Q (Spanish tourist quality symbol); subjects preferred the price to be on the same page as the advertisement that described the hotel, although price range was not one of the most important attributes. A wide range of hotel services was preferred but not essential. No remarks were made or attention paid to room amenities (e.g. air conditioning) or a hotel's surroundings (e.g. topography).

Not all attributes must or can be considered; they must be chosen realistically and in a way that is appropriate to the situation. Gustafsson et al. (1999) suggested a list of rules for choosing attributes when evaluating service quality: choose attributes that are important when the interviewees are buying, ones that can be modified and ones used to compare with competitors. Because there is no consensus in the literature about the elements encompassing each of the positive and negative dimensions of value (Woodruff, 1997), eight relevant attributes were chosen for evaluation:

- Name (one short name 'Majestic Punta Cana' and one long name 'Majestic Colonial Punta Cana Beach Resort Golf Casino \& Spa');

- Hotel's starred rating (four or five stars);

- Phrase used to describe the hotel size (24 buildings with three floors, suites and junior suites; 659 suites and junior suites);

- Picture in the brochure (a general view of the tourist building or a view of the swimming pool);

- Size of the hotel listing (quarter or half page);

- Position in the brochure (right or left page);

- Position on the page (top or bottom);

- Prices (a low price of $€ 277$ or a high price of $€ 499)$

The first five variables were gathered from the qualitative research, and the last three were added by the researchers. Although subjects reported that the hotel listing's position was irrelevant, we incorporated it anyway given the influence product placement has on preferences (Cox, 1970; Chevalier, 1975). To determine high and low prices, we calculated the average ranks of high and low prices from a sample of Santo Domingo hotels published in three brochures.

Quantitative research. For quantitative research, we propose a choice-based conjoint experiment of a sample of undergraduate students who travel in groups. The underlying choice surveys were the statistical design of the experiment, used to allocate all combinations of factors and their levels to form a set of alternatives to be used on the survey. An experimental design is the systematic arrangement of profiles in matrices of coded values researchers use to describe attribute levels representing hypothetical alternatives of marketing options in the choice set. It is not an easy task; Kuhfeld et al. (1994) pointed out that the best designs are discovered when the researcher uses both human design skills and computerized searches.

To design the experiment, we considered eight factors: three quantitative variables (starred ratings, advertisement size and prices) and five qualitative variables (names, descriptions of hotel size, brochure illustrations, positions in the pamphlet and positions on the page). All variables were coded as vectors $(-1,1)$; for factor 1, name, a positive sign indicated the long name 'Majestic Colonial Punta Cana Beach Resort Golf Casino \& Spa', and a negative sign indicated the short name 'Majestic Punta Cana' and so on. Table 1 shows the factors and their codes. A full factorial design would have required a $2^{8}$ factorial experiment (i.e. 256 profiles in the choice set). To avoid saturation of information to respondents, we used a IV resolution design, $2_{\mathrm{IV}}^{8-4}$, a fraction one-sixth of the $2^{8}$ full design. Resolution levels determine the degree of confusion generated by the experiment among factors and interactions between them. A IV resolution design avoids confusion between main effects and second-order interactions, but two-factor interactions are mutually confused. A complete overview of the design of the experiment can be found in Box et al. (2005) and Myers and Montgomery (2002).

Int. J. Tourism Res. (2012)

DOI: $10.1002 /$ jtr 
Table 1. Proposed variables and their codification

\begin{tabular}{|c|c|c|c|}
\hline \multicolumn{2}{|c|}{ Variable } & \multirow{2}{*}{$\frac{-1}{\text { Majestic Punta Cana }}$} & \multirow{2}{*}{$\begin{array}{c}+1 \\
\text { Majestic Colonial Punta Cana } \\
\text { Beach Resort Golf Casino \& Spa }\end{array}$} \\
\hline$A$ & Name & & \\
\hline$B$ & $\begin{array}{l}\text { Hotel rating } \\
\text { (number of starts) }\end{array}$ & 4 & 5 \\
\hline C & Hotel size & $\begin{array}{l}24 \text { buildings of three floors } \\
\text { with suites and junior suites }\end{array}$ & 659 suites and junior suites \\
\hline$D$ & Picture of advertisement & View of building & View of swimming pool \\
\hline E & Hotel listing size & $1 / 4$ of page & $1 / 2$ of page \\
\hline$F$ & Right or left location & Left & Right \\
\hline G & Position on page & On the bottom & On the top \\
\hline$H$ & $\begin{array}{l}\text { Price } 3 \text { days, full-board, service } \\
\text { and airport; transfers included }\end{array}$ & $€ 277$ & $€ 499$ \\
\hline
\end{tabular}

The experimental design required a design generator. A $2^{k-p}$ fractional factorial design necessitates the selection of $p$ independent design generators. A reasonable criterion to select generators is the one with the highest possible resolution. Myers and Montgomery (2002) presented a selection of tables of $2^{k-p}$ fractional factorial designs with the highest resolution for factors below $11(k \leq 11)$. For an experiment of $2_{\mathrm{IV}}^{8-4}$, the generators are $E= \pm B C D, F= \pm A C D$, $G= \pm A B C$ and $H= \pm A B D$. The complete design is shown in Table 2 .
In many cases, it is inappropriate to propose a choice set of 16 profiles either because of the load of work involved in assessing the rank of 16 profiles or because of the difficulties with practical application. It is possible to divide the profile set proposed by the researcher into smaller blocks. Confusion is a design technique for arranging a full or fractional factorial into blocks; the researcher multiplies two or more factors $(A \times B=A B)$ as a criterion to separate the design into smaller blocks. When the model is estimated, the researcher does not know

Table 2. Fractional factorial design

\begin{tabular}{|c|c|c|c|c|c|c|c|c|}
\hline Variables & Name & $\begin{array}{l}\text { umber } \\
\text { f stars }\end{array}$ & $\begin{array}{l}\text { Hotel } \\
\text { size }\end{array}$ & $\begin{array}{c}\text { Picture } \\
\text { advertisement }\end{array}$ & $\begin{array}{l}\text { Advertisement } \\
\text { size }\end{array}$ & $\begin{array}{l}\text { Right or left } \\
\text { location }\end{array}$ & $\begin{array}{l}\text { Position on } \\
\text { page }\end{array}$ & $\begin{array}{l}\text { Price } \\
3 \text { days }\end{array}$ \\
\hline Experiment & $A$ & $B$ & $C$ & $D$ & $E=B C D$ & $F=A C D$ & $G=A B C$ & $H=A B D$ \\
\hline 1 & -1 & -1 & -1 & -1 & -1 & -1 & -1 & -1 \\
\hline 2 & 1 & -1 & -1 & -1 & -1 & 1 & 1 & 1 \\
\hline 3 & -1 & 1 & -1 & -1 & 1 & -1 & 1 & 1 \\
\hline 4 & 1 & 1 & -1 & -1 & 1 & 1 & -1 & -1 \\
\hline 5 & -1 & -1 & 1 & -1 & 1 & 1 & 1 & -1 \\
\hline 6 & 1 & -1 & 1 & -1 & 1 & -1 & -1 & 1 \\
\hline 7 & -1 & 1 & 1 & -1 & -1 & 1 & -1 & 1 \\
\hline 8 & 1 & 1 & 1 & -1 & -1 & -1 & 1 & -1 \\
\hline 9 & -1 & -1 & -1 & 1 & 1 & 1 & -1 & 1 \\
\hline 10 & 1 & -1 & -1 & 1 & 1 & -1 & 1 & -1 \\
\hline 11 & -1 & 1 & -1 & 1 & -1 & 1 & 1 & -1 \\
\hline 12 & 1 & 1 & -1 & 1 & -1 & -1 & -1 & 1 \\
\hline 13 & -1 & -1 & 1 & 1 & -1 & -1 & 1 & 1 \\
\hline 14 & 1 & -1 & 1 & 1 & -1 & 1 & -1 & -1 \\
\hline 15 & -1 & 1 & 1 & 1 & 1 & -1 & -1 & -1 \\
\hline 16 & 1 & 1 & 1 & 1 & 1 & 1 & 1 & 1 \\
\hline
\end{tabular}


whether values correspond to the combined effects of two factors or to individual components. Another design that produces economical and more precise designs for main factors is the two-size block arrangement. We used a design called mirroring where the second profile is arranged with all factors with the sign changed. This design was chosen because it facilitates practical application of the experiment. For building this arrangement, Box et al. (2005) proposed a three-block generator based on two-factor interactions. For example, $B_{1}=A B, B_{2}=A C$ and $B_{3}=A D$. Table 3 shows the reassignment of the 16 profiles into blocks of two.

\section{Field work}

Once the eight-block experiment was configured, it was shown to a number of potential clients to evaluate each experiment by using a ranking scale. The profiles were constructed following the design of the hotel listing shown in the tourist brochures, combining images and texts (Vriens et al., 1998). The scenario that frames the experiment was the choice of a hotel in Santo Domingo for a graduation trip. An example scenario with seven profiles is shown in Appendix A.

Some authors such as Hempel and Daniel (1993) criticize laboratory experiments employed for drawing inferences from experimental situations in which individual choices are manipulated by frames imposed by a researcher. Subjects are often charged with solving problems in a laboratory in which respondents intensify sensitivity to a researcher's instructions, making biassed decisions in comparison with the decisions subjects make on their own in a real environment. To reduce the risks posed by a laboratory, we used familiarity formats similar to a travel agent's brochure. Interviews were conducted during the pre-purchase process when students were organizing trips. We used a mix of profiles, some affected and others placebo. To administer the questionnaire within a frame of reference that facilitates interviewee decisions, each questionnaire contained seven hotel listings: two experimental and five non-exposed advertisements. The dimensions of the frame of reference were seven prices with a range of 285 Euros-235 Euros was the minimum price and 520 Euros the

Copyright (C) 2012 John Wiley \& Sons, Ltd. maximum-a standard deviation of $€ 112.6$, an average trim of $€ 349.6$ and a median of $€ 304$.

Regarding sample size, we used the resource equation proposed by Mead (1988). In this equation, we required at least $n$ runs in blocks of size $n_{\mathrm{b}}$ :

$$
n=\frac{n}{n_{\mathrm{b}}}+\frac{q(q+3)}{2}+n_{\mathrm{lof}}+n_{\mathrm{pe}}
$$

where $q$ is the number of variables, $n_{\text {lof }}$ is a small number of degrees of freedom (typically 5 to 10) for estimating higher-order terms and to check for lack of fit and $n_{\text {pe }}$ is a small number of degrees of freedom (typically 5 to 15) for estimating pure error. In our case, $n_{\mathrm{b}}=2, q=8$, taken as $n_{\text {lof }}+n_{\mathrm{pe}}=15$, the same value used by Gilmour and Trinca (2006). The resource equation suggested a minimum sample of 118 profiles. However, instead of the minimum, we used eight blocks in which two profiles were replicated eight times (i.e. 128 profiles). Each block of the two profiles was shown to eight students. A sample of 64 students from Valladolid University (Spain) who were choosing a destination for their end-of-studies trip participated in the experiment by answering questionnaires during class time. Fieldwork was conducted between February and March 2007. Descriptive statistics show that 58.5\% were female and $41.5 \%$ were male. More than $38.4 \%$ had previous international travel experience. Respondents reported an average age of 22.3 years, and the destinations preferred were the Caribbean $(76.2 \%)$, the Canary Islands (13.3\%) and European cultural cities (9.5\%).

The random utility model provides the economic theory framework for analysing the data from a ranking exercise. This model is derived under the assumption of utility-maximizing behaviour by the decision maker. Under the assumption of independent and identically distributed random error with an extreme value distribution, Beggs et al. (1981) developed a rank-order logit model capable of using all information contained in a survey where alternatives are fully ranked by respondents. Specification is based on repeated application of the probability expression given in Equation (2) until a full ranking of all the alternatives is obtained. This model involves considering each of the choices made by the respondents

Int. J. Tourism Res. (2012)

DOI: $10.1002 /$ jtr 


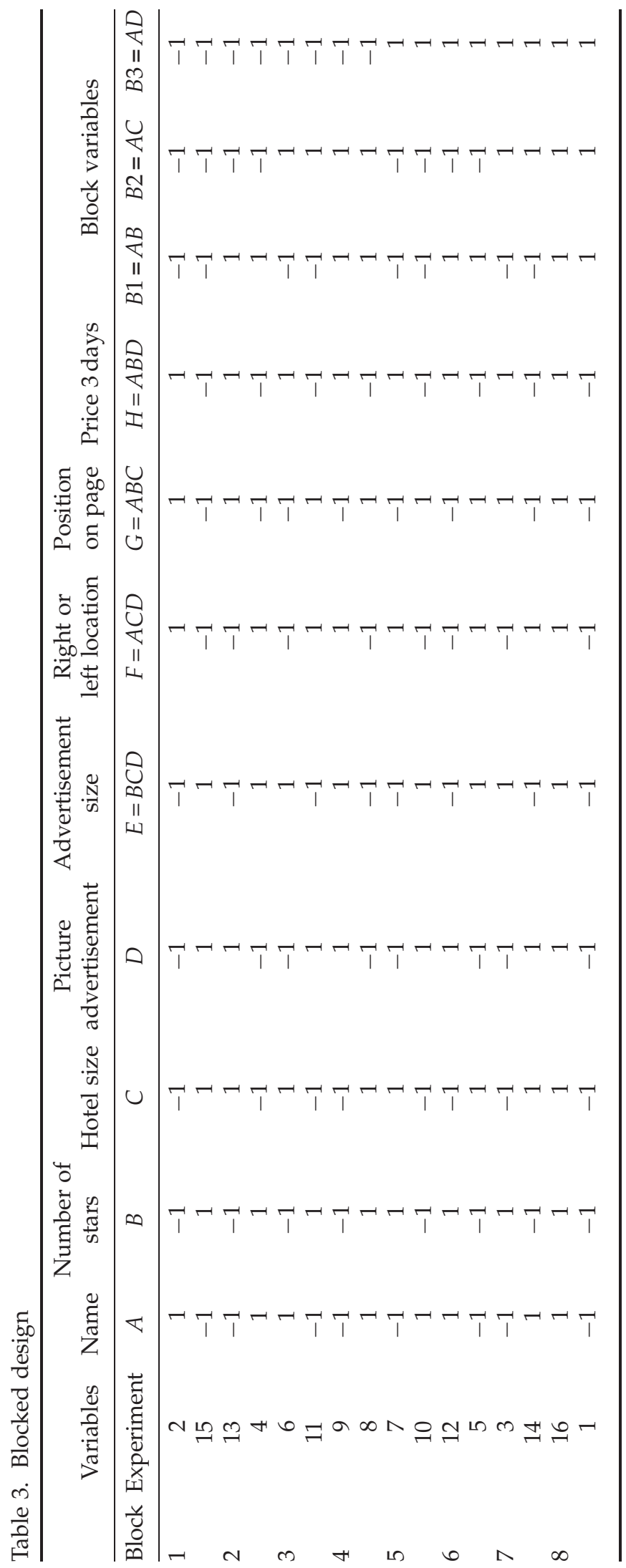


as independent. Each of the choices is called a pseudo-observation because each complete ranking is only one observation formed by multiple pseudo-observations depending on the number of choice sets (Train, 2009). The model considers that the first option is chosen among seven profiles; afterwards, the decision maker chooses the second option among the remains six profiles and so on. The probability of any ranking of an alternative made by individual $i$ can be expressed as a sequence of probability multiplications:

$$
\operatorname{Pi}(U i 1>U i 2>\cdots>U i j)=\prod_{j=1}^{J}\left[\frac{\exp (V i j)}{\sum_{k=j}^{J} \exp (V i k)}\right]
$$

where $\quad V i j=\beta_{0}+\sum_{i=1}^{q} \beta_{i} x_{i}+\varepsilon \quad, \quad P i \quad(U i j)$ measures the probability of this chosen order, $\beta i$ are the values of the slope of the vector for each main factor and $\varepsilon$ is an error term. An ordinal logistic regression model was used to adjust the full profile data in the proportional odds model (or cumulative logit model) by using the PLUM process from SPSS.

\section{RESULTS AND DISCUSSION}

The results of estimation are shown in Table 4. The ordinal logistic regression model has a degree of adjustment usual in this type of study (Cox and Snell's pseudo $R^{2}=0.220 ;-2$ log-likelihood $=160.768, p<0.001)$ (Louviere et al., 2000). To determine whether the model offers adequate predictions, we used two log-likelihood values, comparing two log-likelihood values for the intercept-only model and the final model with the predictors. The chi-square statistic indicates whether the model offers significant improvement over the baseline intercept-only model. The dependent variable had only five of the seven possible values, meaning the two exposed hotel listings were chosen between the first and fifth orders. Hence, the ordinal model estimates only four cut-off values that separate the five response categories. Parameter estimates are shown in Table 4, where four of the 11 effects are significant. These are $B$ (starred ratings), $H$ (size of hotel listing), $E$ (prices) and $B 2$ (the blocking variable). Whereas a variable in

Table 4. Estimated effects from the experimental design $2_{\mathrm{IV}}^{8-4}$

\begin{tabular}{|c|c|c|c|}
\hline Effect & Estimation & Wald & Significance \\
\hline Order $=1$ & -1.004 & 3.562 & 0.059 \\
\hline Order $=2$ & 0.106 & 0.041 & 0.839 \\
\hline Order $=3$ & 1.140 & 4.632 & 0.031 \\
\hline Order $=4$ & 2.211 & 15.842 & 0.000 \\
\hline$A$ & 0.175 & 0.333 & 0.564 \\
\hline$B$ & 0.917 & 8.842 & 0.003 \\
\hline C & -0.456 & 2.254 & 0.133 \\
\hline$D$ & 0.038 & 0.015 & 0.901 \\
\hline$E=B C D$ & 0.924 & 8.950 & 0.003 \\
\hline$F=A C D$ & 0.363 & 1.431 & 0.232 \\
\hline$G=A B C$ & -0.324 & 1.143 & 0.285 \\
\hline$H=A B D$ & -0.661 & 4.682 & 0.030 \\
\hline$B 1=A B=C G=D H=E F$ & -0.476 & 2.453 & 0.117 \\
\hline$B 2=A C=B G=D F=E H$ & 0.803 & 6.826 & 0.009 \\
\hline$B 3=A D=B H=C F=E G$ & 0.174 & 0.332 & 0.565 \\
\hline \multicolumn{4}{|c|}{ Pseudo $R$-square } \\
\hline Cox and Snell & 0.220 & & \\
\hline Nagelkerke & 0.225 & & \\
\hline McFadden & 0.066 & & \\
\hline $\begin{array}{l}\text { Diagnostic -2 log- } \\
\text { likelihood }\end{array}$ & 160.768 & & 0.001 \\
\hline
\end{tabular}


statistical design experiment can be interpreted singly if there is no evidence that it is confused with another, B2 (the blocking variable) is confused with several second-order interactions, $B 2=A C=V G=D F=H E$; interpretation is, therefore, imprecise. We suspect that the value of $B 2$ responds significantly to the interaction between $H$ (size of hotel listing) and $E$ (prices).

To verify these results, we considered the analysis of only three factors, those which demonstrated significance after the first experiment of the three main effects $(B, H$ and $E)$. Because only three factors were significant, a full factorial of $2^{3}$ required eight profiles drawn from the previous design using 16 profiles. This is possible because any fractional factorial design of resolution $R$ may contain complete factorials in any sub-group of $R-1$ variables. Because the design is resolution $R \mathrm{IV}$, it was possible to configure a complete factorial design with these three variables. This design allows estimation of main effects and interactions without any confusion patterns and, consequently, allowed direct interpretation. Ordinal logistic regression was used to evaluate significance of the effects. Table 5 shows the model-fitting information and the estimated

Table 5. Estimated effects from the experimental design $2^{3}$

\begin{tabular}{|c|c|c|c|}
\hline Effect & Estimation & Wald & Significance \\
\hline Order $=1$ & -0.850 & 3.771 & 0.052 \\
\hline Order $=2$ & 0.247 & 0.331 & 0.565 \\
\hline Order $=3$ & 1.249 & 7.962 & 0.005 \\
\hline Order $=4$ & 2.281 & 23.423 & 0.000 \\
\hline$B$ & 0.907 & 8.756 & 0.003 \\
\hline$E$ & 0.859 & 7.894 & 0.005 \\
\hline$H$ & -0.663 & 4.760 & 0.029 \\
\hline$B H$ & 0.149 & 0.246 & 0.620 \\
\hline$B E$ & -0.110 & 0.133 & 0.716 \\
\hline$H E$ & 0.827 & 7.314 & 0.007 \\
\hline BHE & -0.298 & 0.979 & 0.322 \\
\hline \multicolumn{4}{|c|}{ Pseudo $R$-square } \\
\hline Cox and Snell & 0.170 & & \\
\hline Nagelkerke & 0.177 & & \\
\hline McFadden & 0.058 & & \\
\hline $\begin{array}{l}\text { Diagnostic -2 } \\
\text { log- } \\
\text { likelihood }\end{array}$ & 100.845 & & 0.000 \\
\hline
\end{tabular}

Copyright (C) 2012 John Wiley \& Sons, Ltd. effects from the derivative model. Values are similar to the previous analysis.

$H$ (prices) had a negative impact on evaluation by the sample. This result is in accord with the interpretation of price as sacrifice; the lower the price, the greater the customer's evaluation. Other more highly valued effects were as follows: $B$ (starred ratings), $E$ (hotel listing size) and $H E$ (interaction between price and size of hotel listing). $B$ (starred ratings) and $E$ (advertisement size) had a positive influence on the subjects' evaluation. Respondents used both factors as external value cues; the higher the starred ratings and the bigger the size of the advertisement, the greater its evaluation. Moreover, the joint presence of $H E$ (interaction between price and size of hotel listing) increased positive valuation. The dual role of price as sacrifice and extrinsic cue of service quality is appreciated when price interacts with a large advertisement. Thus, a negative evaluation represented by high price accommodation is offset by a large advertisement. Likewise, the positive influence generated by a large advertisement increases with price.

\section{CONCLUSIONS}

Customer evaluation and decision making are primary targets in all areas of business, particularly in tourism management. To understand customer needs and determine the primary factors of perceived value, a researcher can ask subjects directly or deduce desires through indirect methods such as experimentation. In this study, we demonstrate the process of implementing a choice-based conjoint analysis and how this analysis can be used as a powerful tool for evaluating preferences. These designs are particularly suitable for subjects related to demand for introduction of new products, line extensions (Louviere et al., 2000) or design of a new hotel listings in a tourist brochure. In addition to providing an evaluation of the weight of main attributes, it also shows the weight of interactions of several attributes.

Value perceptions depend on a frame of reference in which consumers make evaluations. Employing an experimental design in a context of pre-purchase with a static frame of reference, we examined the main factors of 
value perception in the process of choosing a hotel from a travel agent brochure. Subjects used a reduced number of attributes to infer perceived quality and the sacrifice necessary to acquire it. In this case, only three of the eight attributes were significant: advertisement size (quarter or half page) and the hotel's starred rating (4 or 5) as quality attributes, and price indicating sacrifice. For this market segment of students in their final year of university, brochure illustration was not significant in spite of the results from qualitative research, neither were position on page, nor name of establishment, nor left versus right location, although results are in line with the qualitative research. Hotel size occupies an intermediate position of importance; an increase in sample size is necessary to verify the variable's influence on selection.

Attributable to the second analysis using a full factorial design, it was possible to detect the second inductive factor of perceived quality consisting of the joint presence of two variables, advertisement size (quarter or half page) and price. The two joint variables demonstrate the dual role of price (Dodds et al., 1991), as a sacrifice people must make to buy goods or as an extrinsic cue of service quality, when it interacts with a large advertisement. Interaction between price and hotel listing size showed a positive result when negative was expected, suggesting some kind of compensatory effect. These findings have important implications for managers, specifically that a higher price expected to generate negative utility is offset by a larger advertisement to produce a positive effect on a tourist's final decision. The increased cost of a larger advertisement could be recouped by charging a higher price for the trip and hotel room.

This study considers perceived value attributes in a pre-purchase stage, a stage traditionally understudied. Knowing which aspects or attributes determine perceived value of the product before purchasing is extremely useful for businesses and managers. A travel agent brochure may be giving more prominence to elements that do not determine perceived value of a tourist, making communications ineffective and not contributing to a consumer's decision. However, the validity of the attributes of perceived value disappears with purchase. Fisher et al. (1994) argued that when consumers evaluate perceived service quality after purchase, they rarely mention the criteria used for evaluation before purchase; when they do, such criteria are relegated to a lower hierarchic level to the one occupied before purchase.

This study has some limitations. Participants were from one university, disallowing statistical inferences from the sample to a population. Some variables such as room quality and hotel location were ignored as potentially relevant attributes. The laboratory environment that afforded internal validity because of environment control compromised external validity because of an artificial venue. The sample size was also a limiting factor because it did not allow us to determine the significance of some primary variables (e.g. hotel size), although the model using ordinal logistic regression was proposed because of its suitability to fit small samples. Designing this experiment, we transformed a full fractional model into a fractional one; the resulting design was organized into blocks of two. This design only allows the estimation of main factors without interactions. The design could be improved by taking advantage of multiple runs and using a fractional factorial with higher resolution such as $R \mathrm{~V}$, although there is the disadvantage of the cost of designing 32 brochures instead of eight. The model helped us get closer to customers, identifying opinions and preferences; it was a simple procedure that facilitated sequential research that enabled us to continuously improve knowledge of the subject. 
Appendix A

Example of experimental travel agent brochure

Punta Cana

The package includes:

-4 days/ 3 nights. Daily Departures

- Transfer from Santo Domingo or Punta Cana airports/ hotel /Santo Domingo or Punta Cana airports

- Hotel Accommodation as described in the brochure

\section{HOTELS \\ Playa Bávaro}

5. SECRET EXELLENCE PUNTA CANA *****

Uvero Alto. Higüey. PUNTA CANA. Tel.: (809) 6589880

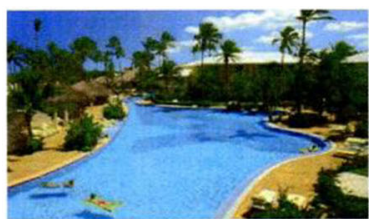

A resort hotel located on a golden, palm-lined beach. It has 446 rooms distributed across 13 two- and threebathroom and jacuzzi, hairdryer, telephone, TV, iron, mini-bar and safe. storey buildings, each equipped with

\section{SUNSCAPE THE BEACH PUNTA CANA ****}

Playas uvero Alto. PUNTA CANA. Tel.: (809) 6820404

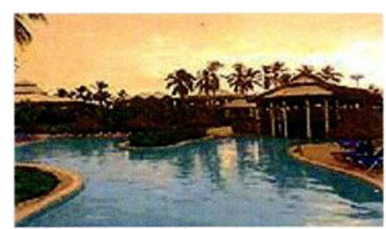

Situated on the north-east coast of the Dominican Republic, the hotel has a wide range of rooms, all with balcony or terrace with sea views, as well as tennis courts and gardens. The rooms are equipped with bathroom, hairdryer, air conditioning, ceiling fan, telephone, satellite TV, safe and 24-hour room service.

The complex is also provides restaurants, bars, swimming pool, gymnasium, The hotel complex has 6 restaurants, one with buffet service, 7 bars shops and water sport facilities. Price: 520 euros.

including the lobby bar and swimming pool bar, large swimming pools in the shape of a river, Jacuzzis, spa, tennis courts, shop and car rental service. Price. 304 euros.

\section{MAJESTIC COLONIAL PUNTA CANA BEACH RESORT GOLF CASINO \& SPA ***** Playa Bávaro. Higüey. PUNTA CANA. Tel.:(809) 2219898}

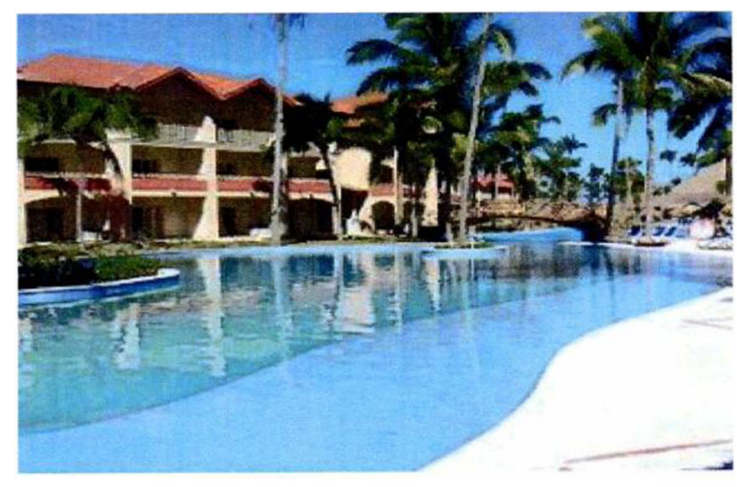

There are also 7 restaurants, 8 bars, daytime and night-time entertainment, mini-club, tennis courts, water polo, catamaran, Jacuzzis, gymnasium and spa. Price: 499 euros

The hotel is located at Arena Gorda, Playa Bávaro. It consists of 24 threestorey buildings with en suite and junior suite rooms, all finished with quality materials. Rooms are provided with hairdryer, air conditioning, ceiling fan, satellite TV, mini-bar, safe, coffee-maker and terrace.

\section{Right Page}




\section{REFERENCES}

Ajzen I, Madden TJ. 1986. Prediction of goal-directed behavior: attitudes, intentions, and perceived behavioral control. Journal of Experimental Social Psychology 22(5): 453-474.

Andereck KL. 2005. Evaluation of a tourist brochure. Journal of Travel \& Tourism Marketing 18(2): 1-13.

Beggs S, Cardell S, Hausman J. 1981. Assessing the potential demand for electric cars. Journal of Econometrics 17(1): 1-19.

Bieger T, Laesser C, Gallen S. 2000. Segmenting travel situations on the basis of motivation and information-collection by the traveller. Revue de Tourisme 2: 54-64.

Box EP, Hunter JS, Hunter WG. 2005. Statistics for experimenters: design, innovation, and discovery. 2ndedn . Wiley: Hoboken.

Chevalier M. 1975. Increase in sales due to in-store display. Journal of Marketing Research 12(4): 426-431.

Chiou WB, Wan CS, Lee HY. 2008. Virtual experience vs brochures in the advertisement of scenic spots: How cognitive preferences and order effects influence advertising effects on consumers. Tourism Management 29(1): 146-150.

Cox KK. 1970. The effect of shelf space upon sales of branded products. Journal of Marketing Research 7(1): 55-58.

Dellaert B, Ettema D, Lindh C. 1998. Multi-faceted tourist travel decisions. a constraint-based conceptual framework to describe tourist's sequential choices of travel components. Tourism Management 19(4): 313-320.

Dodds WB, Monroe, KB, Grewal D. 1991. Effects of price, brand and store information on buyers' product evaluations. Journal of Marketing Research 28(4): 307-319.

Dowling G, Staelin R. 1994. A model of perceived risk and intended risk-handling activity. Journal of Consumer Research 21(1): 119-134.

Elrod T, Chrzan K. 2007: The value of extent-ofpreference information in choice-based conjoint analysis. In Conjoint Measurement. Methods and Applications, 4thedn, Gustafsson A, Herrmann A, Huber F (eds). Springer: Berlin; 133-144.

Elrod T, Louviere JJ, Davey KS. 1992. An empirical comparison of ratins-based and choice-based conjoint models. Journal of Marketing Research 29(3): 368-377

Erickson, GM, Johansson, JK. 1985. The role of price in multi-attribute product evaluations. Journal of Consumer Research 17: 195-199.

Fishbein M, Ajzen I. 1975. Belief, attitude, intention and behavior: an introduction to theory and research. Addison-Wesley: New York.
Fisher S, Clemons D, Scott, R, Woodruff D, Schumann W, Burns MJ.1994. Comparing consumers' recall of prepurchase and postpurchase product evaluation experiences. Journal of Consumer Research 20(2): 548-560.

Fodness D, Murray B. 1999. A model of tourist information search behaviour. Journal of Travel Research 37(3): 220-230.

Frank RH. 2009. Microeconomics and behavior. Mc Graw-Hill: New York

Gallarza MG, Gil I. 2006. Value dimensions, perceived value, satisfaction and loyalty: an investigation of university students' travel behaviour. Tourism Management 27(3): 437-452.

Gilmour SG, Trinca LA. 2006. Response surface experiments on processes with high variation. In Response Surface Methodology and Related Topics, Khuri AI (ed.). World Scientific Publishing Co: New York; 19-46.

Gupta A, Bo-Chiuan S, Walter Z. 2004: An empirical study of consumer switching from traditional to electronic channels: a purchase-decision process perspective. International Journal of Electronic Commerce 8(3): 131-161.

Gustafsson A, Ekdahl F, Bergman B. 1999. Conjoint analysis: a useful tool in the design process. Total Quality Management 10(3): 327-343.

Haaijer R, Wedel M. 2007. Conjoint choice experiments: general characteristics and alternative model specifications. In Conjoint Measurement. Methods and Applications, 4thedn , Gustafsson A, Herrmann A, Huber F (eds). Springer: Berlin; 199-229.

Hanley N, Mourato S, Wright RE. 2001. Choice modelling approaches: a superior alternative for environmental valuation?. Journal of Economic Surveys 15(3): 435-462

Hauser JA, Urban GL. 1986. The value priority hypotheses for consumer budget plans Journal of Consumer Research 12(4): 446-462.

Hempel DJ, Daniel HZ. 1993. Framing dynamics: measurement issues and perspectives. Advances in Consumer Research 20: 273-279.

Hodgson P. 1993. Tour operator brochure design research revisited. Journal of Travel Research 32(1): 50-52.

Hsieh S, O'Leary L. 1993. Communication channels to segment pleasure travelers. Journal of Travel $\mathcal{E}$ Tourism Marketing 2(2/3): 57-76.

Klein R. 1990. New techniques for listening to the voice of the customer. Applied Marketing Science, Inc., Second Symposium on Quality Function Deployment, June 18-19, 1990. Cited by Cohen L. 1995. Quality Function Deployment: How to Make QFD Work for You. Addison-Wesley Publishing Company, Reading, Massachusetts, USA.

Int. J. Tourism Res. (2012)

DOI: $10.1002 /$ jtr 
Kotler P. 2000. Marketing Management. The Millennium Edition. Prentice Hall Inc: New Jersey.

Kuhfeld WF, Tobias RD, Garratt M. 1994. Efficient experimental design with marketing applications. Journal of Marketing Research 31(4): 545-557

Lee C-K, Yoon Y-S, Lee S-K. 2007. Investigating the relationships among perceived value, satisfaction and recommendations: the case of Korean DMZ. Tourism Management 28(1): 204-214.

Louviere JJ, Hensher, DA, Swait JD. 2000. Stated Choice Methods. Cambridge University Press: Cambridge.

Mead R. 1988. The design of experiments. Cambridge: Cambridge University Press; cited by Gilmour SG, Trinca L A. 2006. Response surface experiments on processes with high variation. In Response Surface Methodology and Related Topics, Khuri AI (ed.). World Scientific Publishing Co: New York.

Molina A, Esteban A. 2006. Tourism brochures: usefulness and image. Annals of Tourism Research 33(4): 1036-1056.

Moliner MA, Rodríguez RM, Callarisa L1 J, Sánchez J. 2005. Dimensionalidad del valor percibido global de una compra. Revista Española de Investigación de Marketing 9(2): 135-157.

Munger JL, Grewal D. 2001. Effects of alternative price promotional methods on consumers' evaluation and purchase intentions. Journal of Product E Bran Management 10(3): 185-197.

Myers RH, Montgomery DC. 2002. Response Surface Methodology. John Wiley \& Sons, Inc: New Jersey.

Naylor G, Frank, KE. 2001. The effect of price bundling on consumer perceptions of value. Journal of Services Marketing 15(4): 270 - 281.

Nicolau JL, Mas FJ. 2006. Elección de la duración vacacional: una aproximación con modelos de recuento. Revista Europea de Dirección y Economía de la Empresa 15(2): 99-116.

Ortega E, Rodriguez B. 2007. Information at tourism destinations. Importance and cross-cultural differences between international and domestic tourist. Journal of Business Research 60(2): 146-152.

Ostrom A, Iacobucci D. 1995. Consumer trade-offs and the evaluation of services. Journal of Marketing 59(1): 17-28.

Rao, VR, Sattler, H. 2007. Measurement of price effects with conjoint analysis: separating informational and allocative effects of price. In Conjoint Measurement. Methods and Applications, 4thedn , Gustafsson A, Herrmann A, Huber F (eds). Springer: Berlin; 31-46.

Rewtrakunphaiboon W, Oppewal H. 2008. Effects of package holiday information presentation on destination choice. Journal of Travel Research 47(2): 127-136.
Roehl W, Fesenmaier D. 1992. Risk perceptions and pleasure travel: an exploratory analysis. Journal of Travel Research 30(4): 17-26.

Scarpa R, Rose JM. 2008. Design efficiency for nonmarket valuation with choice modeling: how to measure it, what to report and why. The Australian Journal of Agricultural and Resource Economics 52(3): 253-282.

Spiggle S. 1994. Analysis and interpretation of qualitative data in consumer research. Journal of Consumer Research 21(3): 491-503.

Street D, Burgess L. 2007. The Construction of Optimal Stated Choice Experiments: Theory and Methods. Wiley: Hoboken, NJ.

Tax S, Brown SW, Chandrashekaran M. 1998. Customer evaluation of service complaint experiences: implications for relationship marketing. Journal of Marketing 62(April): 60-76.

Teas RK, Agarwal, S. 2000. The effects of extrinsic product cues on consumer's perceptions of quality, sacrifice and value. Journal of the Academy of Marketing Science 28(2): 278-290.

Teichert T, Shehu, E. 2007. Evolutionary conjoint. In Conjoint Measurement. Methods and Applications, 4thedn , Gustafsson A, Herrmann A, Huber F (eds). Springer: Berlin; 295-320.

Train K. 2009. Discrete Choice Methods with Simulation. 2ndedn, Cambridge University Press: Cambridge.

Vriens M, Loosschilder, G, Rosbergen E, Wittink D. 1998. Verbal versus realistic pictorial representations in conjoint analysis with design attributes. Journal of Product Innovation Management 15(5): 455-467.

Wicks BE, Schuett MA. 1991. Using travel brochures to target frequent travelers and "big-spenders". Journal of Travel \& Tourism Marketing 2(3): 77-90.

Wittink DR, Cattin P. 1989. Commercial use of conjoint analysis: an update. Journal of Marketing 53(3): 91-96.

Woodruff BR. 1997. Customer value: the next source for competitive advantage. Journal of the Academy of Marketing Science 25(2): 139-153.

Yamamoto D, Gill AM. 1999. Emerging trends in Japanese package tourism. Journal of Travel Research 38(2): 134-143.

Zeithaml VA. 1988. Consumer perceptions of price, quality and value: a means-end model and synthesis of evidence. Journal of Marketing 52(3): 2-22.

Zhou Z. 1997. Destination marketing: measuring the effectiveness of brochures. Journal of Travel $\mathcal{E}$ Tourism Marketing 6(3): 143-158. 